\title{
Bilateral Tibial Tubercle Fracture in Adolescence: A Case Report and Review of the Literature
}

\section{Panagiotis Poulios $^{1 *}$, Athanasios Serlis ${ }^{1}$, Livio Di Mascio ${ }^{2}$, Adrian Carlos $^{2}$, Alexandros Vris ${ }^{2}$ and Georgios Konstantopoulos ${ }^{2}$}

${ }^{1}$ Newham University Hospital, Orthopaedic Department, United Kingdom

${ }^{2}$ Royal London Hospital, Orthopaedic Department, United Kingdom

*Corresponding Author: Panagiotis Poulios, Newham University Hospital, Orthopaedic Department, United Kingdom.
Received: November 13, 2020

Published: November 27, 2020

(C) All rights are reserved by Panagiotis

Poulios., et al.

\begin{abstract}
Background: Fractures of the tibial tubercle are relatively uncommon injuries. Bilateral tibial tubercle fractures are substantially rare; particularly the high-grade patterns. These types of fractures occasionally involve the growth plate, extend through the articular surface and have a reasonable good prognosis despite their bilateral nature. The available literature body is supporting the surgical fixation of these injuries, while there are no reports for conservative management. In this manuscript, we report satisfactory outcomes with conservative management and close follow-up.

Case Summary: In this article, we report an Ogden type IVA simultaneous bilateral tibial tubercle fractures in a 12-year-old boy after a reported ground-level fall during sporting activity. These injuries were managed conservatively with close follow-up and repeat imaging. Clinical and radiological results were excellent at the final review.

Conclusion: The bilateral tibial tubercle fractures are a rare injury in the paediatric population. The majority of the reported cases in the literature support surgical fixation as the choice of treatment. In this case, we report satisfactory outcomes with conservative management and close follow-up, and we review the relevant literature.
\end{abstract}

Keywords: Bilateral; Tibial Tubercle; Fracture; Conservative; Paediatric; Case Report

\section{Introduction}

Fracture of the tibial tubercle is an uncommon injury. The occurrence ranges from 0.4 to $2.7 \%$ of all epiphyseal injuries in the paediatric population 6. Bilateral fractures of the tibial tuberosities are extremely rare. So far, only nine cases have reported, six simultaneous and three sequential. It occurs during the period of rapid growth when the physis is undergoing physiologic changes and therefore is more susceptible to injury 6-10; The formative stage occurs with the closure of the growth plate at 15 in girls and 17 years in boys.

This paper aims to review the existing literature body and report a case of conservatively controlled simultaneous bilateral tibial tubercle fracture. Additionally, we want to demonstrate that this particular injury in the adolescents heals well despite its bilateral nature without incidence of deformity or functional compromise even with conservative treatment with a relatively brief period of immobilisation.

\section{Case Presentation}

A 12-year-old well-developed male came in the A\&E after a ground-level reported fall on his knees, because of inability to ambulate, pain and significant swelling immediately after the injury. After the patient managed according to the ATLS protocols, it was confirmed the isolated bilateral injury. The patient had pain (VAS: 7/10). There was significant (Grade +3 ) swelling of his knees, more pronounced at the distal pole of the patella with an element of bruising, without however abrasions or lacerations. The skin was intact, without evidence of tending. The peripheral pulses were palpable and symmetric bilaterally. The extremity was warm and 
well perfused. The gross sensor motor examination of the extremities was intact and documented. The compartments were soft and not tender at the palpation. The passive stretch of the muscle compartments elicited pain, but not consistent with impending compartment syndrome.

The patient was not able to perform the straight leg raise test and maintain the knee extension, even with the elimination of gravity, by performing the test in lateral decubitus position. The range of motion of the knees was limited due to the pain and apprehension, and the patient was not able to comply with the rest physical examination.

\section{Imaging investigations/examinations}

A bilateral widening of tibial tubercles with an element of partial fragmentation was revealed in the x-ray survey (Figure 1). Of note, the patient had a reported Osgood-Schlatter past.
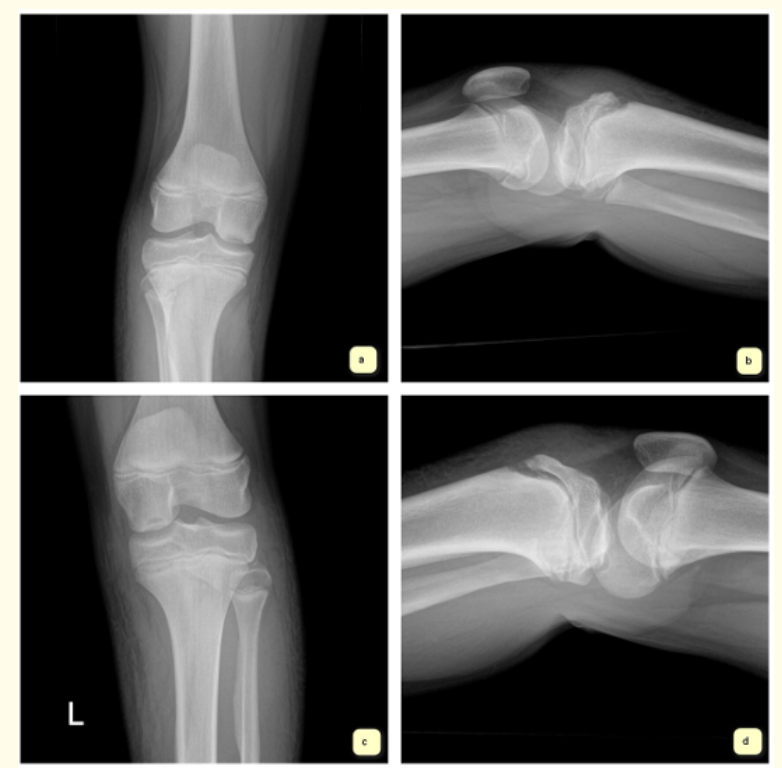

Figure 1: Plain orthogonal $x$-ray films of the right ( $a$ and $b$ ) and left knee ( $c$ and d) respectively, depicting bilateral avulsion fractures of the tibial tubercles, grade Iva.

The patient admitted for neurovascular observation, pain management and further investigation with MRI scan.

The MRI scan was significant for bilateral tibial tubercle fractures, Ogden type IVA variance, without soft tissue interposition and intraarticular involvement. An accidental finding was a bilateral OCD lesion of the femoral condyles (Figures 2 and 3).
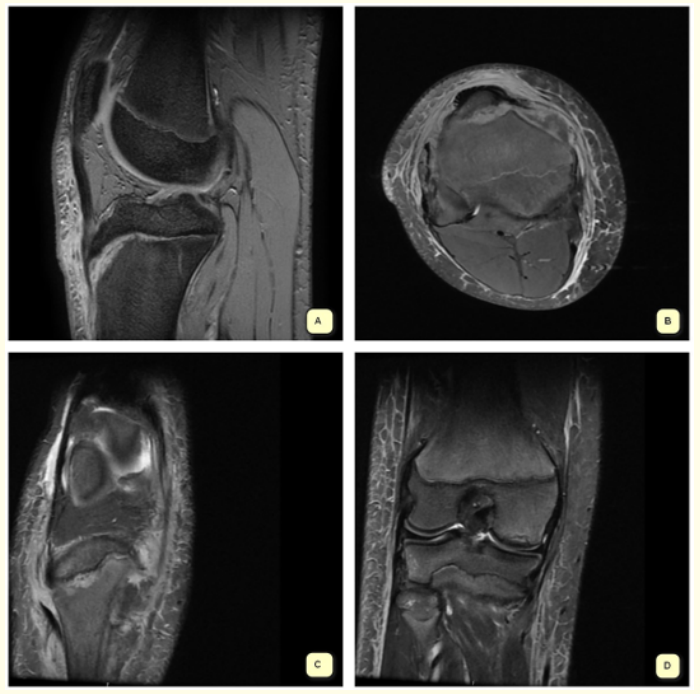

Figure 2: MRI images of the right knee, demonstrating a fracture through the proximal tibial physis equivalent to a grade IV Ogden fracture. Note the metaphyseal posterior "Thurston -Holland" fragment at panel A.
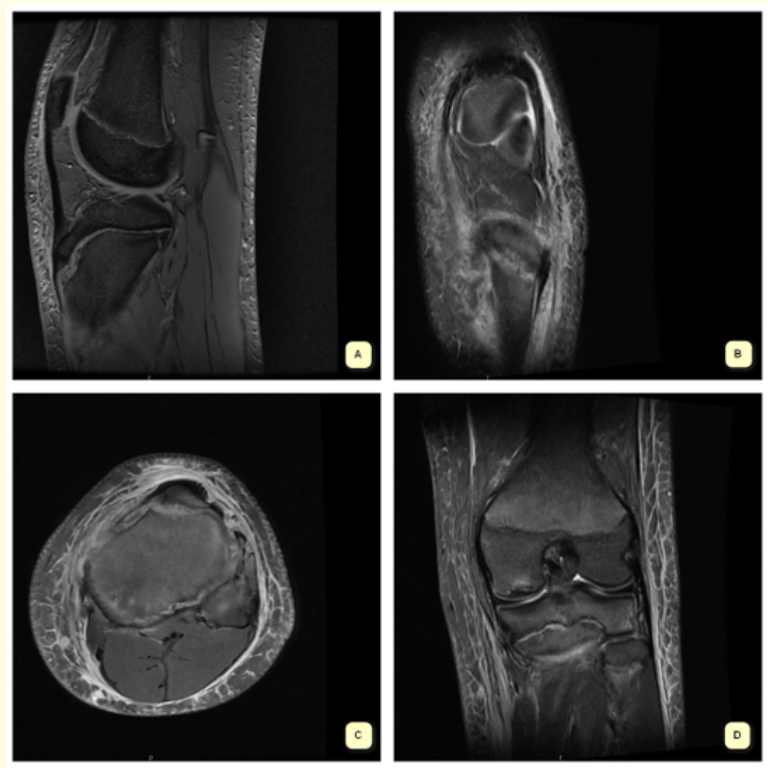

Figure 3: MRI images of the Left knee, demonstrating a fracture through the proximal tibial physis equivalent to a grade IV Ogden fracture. Note the metaphyseal posterior "Thurston -Holland" fragment (smaller than the right side) at the panel A. 


\section{Treatment}

A decision for conservative treatment was made. Immobilisation with a knee brace locked in extension for two weeks, partial weight-bearing as tolerated and frequent follow up in the outpatient clinic.

The plan for the knee brace is to increase the flexion by 30 degrees increments every two weeks up to the six weeks.

Outcome and follow up.

From the planned clinical review of the patient in the outpatient clinic, he reported that his pain was manageable with simple over-the-counter analgesics. He denied constitutional symptoms and red flag signs. The range of motion was limited but increased since the previous examination.

He was using crutches and a knee brace locked in 30 degrees of flexion.

The new X-rays reviewed and were satisfactory. It was advised knee brace locked in 60 degrees of flexion, continue the physiotherapy regime and a clinical review in one month.

From the latest clinical appointment, there was a significant improvement. The boy was able to weight bear fully, with minimal aid from the crutches. However, he was not compliant with the knee brace.

The patient was able to perform straight leg raise, but only to maintain it for 3 secs. The passive range of motion was a full extension and flexion up to 80 degrees, whereas, the active extension lag by 10-15 degrees and the flexion up to 60 degrees. The patella tracking was regular. The knee joints were stable.

The X-rays were satisfactory, and the healing process of the fractures was apparent (Figure 4).

The treatment plan was to discard the brace and allow full range of motion with full weight-bearing status. The patient should continue the physiotherapy and to have another clinical review in two months.

Because of the new COVID-19 limitations, the latest analysis was done via video call. The patient had a full functioning bilateral range of motion from the examination, able to ambulate indoors without crutches. It has been recorded that when squatting and transitioning from sitting to standing, there was a mild pain in the quadriceps bilaterally, that eases instantly. Overall, his advances have been satisfactory.

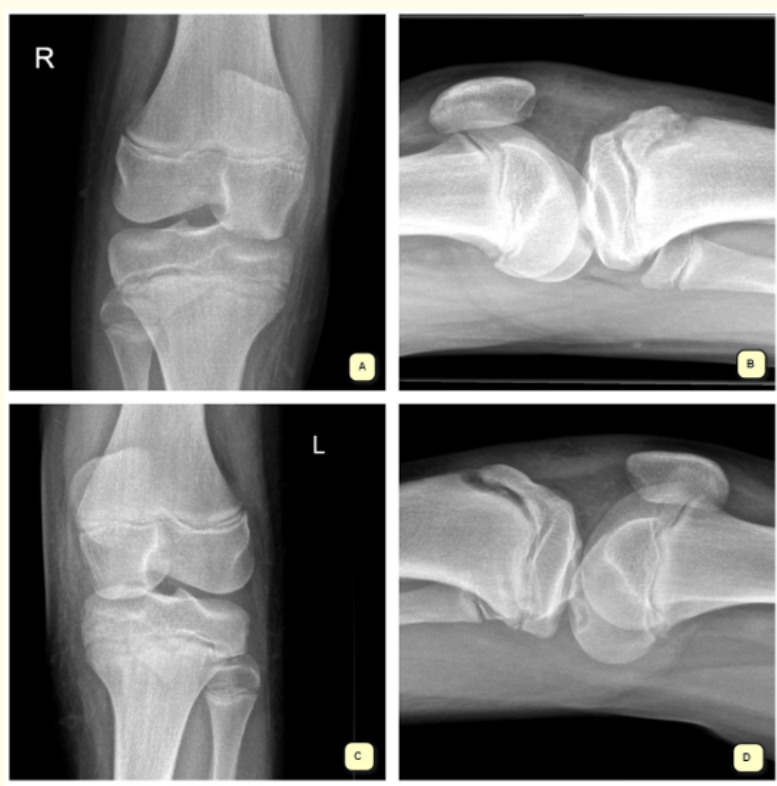

Figure 4: Plain radiographs of the right and the left knee, 13- days post injury.

\section{Discussion}

Fractures through the proximal tibial growth plate (physis) are relatively infrequent but high-grade, bilateral metaphyseal tibial tubercle fractures are substantially rare [1-3]. Of the 12 simultaneous bilateral fractures in six patients, eight were Watson-Jones type III, one was Watson-Jones type II, and three were Ryu and Debenham type IV fractures. This paper reports another case of bilateral fractures type IV, but this is unique because the case was treated conservatively with closed reduction and a knee brace. The previously reported cases over the past 60 years are summarised in table 1.

In all the cases, the patients were males who involved in physical activity. The youngest was 12 years old and the oldest 17 years old with a mean age around 14.6 years old. Interestingly, the most commonly affected age group was 15 years old. Another feature of interest was that there was a notable correlation with preexisting Osgood- Schlatter's Disease (OSD). All the cases were treated with open reduction and internal fixation with screws except for a patellar sleeve fracture which was treated with suture anchors (Desai RR., et al.). All reported fair results and the complication rate was low, with compartment syndrome (McKoy BE., et al.) to be the most severe complication. 


\begin{tabular}{|c|c|c|c|c|c|c|}
\hline & $\begin{array}{l}\text { Type of fracture } \\
\text { (classification) }\end{array}$ & $\begin{array}{c}\text { Operative } \\
\text { treatment }\end{array}$ & Type of fixation ORIF & year & $\begin{array}{l}\text { Patient's } \\
\text { age }\end{array}$ & Complications \\
\hline Ergun M., et al. & B/L II & Yes & Tension band wiring & 2003 & 16 & $\begin{array}{l}\text { Metal work } \\
\text { removed at } 10 \\
\text { weeks }\end{array}$ \\
\hline Henard DC., et al. & B/L III & Yes & $\begin{array}{l}\text { Left wire pinning } \\
\text { Right screw } \\
\text { fixation }\end{array}$ & 1983 & 15 & \\
\hline Lepse PS., et al. & $\begin{array}{l}\text { Right side IIIB } \\
\text { Left side IIA }\end{array}$ & Yes & Screw fixation & 1988 & 14 & \\
\hline Maar DC., et al. & B/L III & Yes & Screw fixation & 1988 & 16 & $\begin{array}{l}\text { Removal of } \\
\text { prominent implant } \\
\text { at } 3 \text { years }\end{array}$ \\
\hline Mirly HL., et al. & 1 & B/L III & yes & $\begin{array}{l}\text { Screw } \\
\text { fixation }\end{array}$ & 14 & \\
\hline Mosier SM., et al. & $\begin{array}{l}\text { Right side IV } \\
\text { Left side III }\end{array}$ & Yes & Screw fixation & 2004 & 15 & \\
\hline Siebert CH., et al. & $\begin{array}{l}\text { Right side II } \\
\text { Left side I }\end{array}$ & Yes & Screw fixation & 1995 & 16 & \\
\hline Georgiou G., et al. & B/L IIIB & Yes & Screw fixation & 2018 & 17 & \\
\hline $\begin{array}{l}\text { Hamilton SW., et } \\
\text { al. }\end{array}$ & $\begin{array}{c}\text { type I on the right } \\
\text { and type II on the } \\
\text { left }\end{array}$ & Yes & Screw fixation & 2006 & 13 & \\
\hline McKoy BE., et al. & B/L IV & Yes & Screw fixation & 2006 & 15 & $\begin{array}{l}\text { Compartment syndrome of } \\
\text { right leg, recurrent } \\
\text { avulsion of left } \\
\text { tibial tubercle at } \\
1 \text { year }\end{array}$ \\
\hline $\begin{array}{l}\text { Arredondo-Gómez } \\
\text { E., et al. }\end{array}$ & $\begin{array}{l}\text { Right side IIIA } \\
\text { Left side IIIB }\end{array}$ & Yes & Screw fixation & 2007 & 14 & \\
\hline $\begin{array}{l}\text { Slobogean GP., } \\
\text { et al. }\end{array}$ & $\begin{array}{l}\text { Left side IV } \\
\text { Right side III }\end{array}$ & $\begin{array}{l}\text { Left (closed } \\
\text { reduction) }\end{array}$ & Screw fixation & 2006 & 16 & $\begin{array}{l}\text { Flexion deformity } \\
\text { at } 16 \text { months } \\
\text { follow up on right } \\
\text { side }\end{array}$ \\
\hline $\begin{array}{l}\text { Khodadadyan- } \\
\text { Klosterman C., } \\
\text { et al. }\end{array}$ & $\begin{array}{l}\text { Right side IIIB } \\
\text { Left side IIA }\end{array}$ & Yes & Screw fixation & 2003 & 15 & \\
\hline Elbaum R., et al. & B/L III & Yes & Screw fixation & 2011 & 16 & \\
\hline Desai RR., et al. & $\begin{array}{l}\text { sleeve avulsion } \\
\text { fracture } \\
\text { (type V) }\end{array}$ & Yes & suture anchor fixation & 2013 & 12 & \\
\hline Tulic G., et al. & $\begin{array}{l}\text { Right side II } \\
\text { Left side IV }\end{array}$ & Yes & Screw fixation & 2010 & 15 & \\
\hline
\end{tabular}




\begin{tabular}{|c|c|c|c|c|c|c|}
\hline Hanley C., et al. & $\begin{array}{c}\text { Right IA } \\
\text { Left side IIIA }\end{array}$ & Yes & Screw fixation & 2008 & 15 & \\
\hline Khoriatti AA., et al. & $\begin{array}{l}\text { Right side III } \\
\text { Left side II }\end{array}$ & Yes & Screw fixation & 2015 & 17 & \\
\hline $\begin{array}{l}\text { Borsch-Madsen P., } \\
\text { et al. }\end{array}$ & B/L III & Yes & Screw fixation & $1954 / 55$ & 17 & $\begin{array}{l}\text { Removal of screw } \\
\text { due to skin erosion }\end{array}$ \\
\hline Jaime et. Al. & $\begin{array}{l}\text { Right side IB } \\
\text { Left side IIIA }\end{array}$ & Yes & $\begin{array}{l}\text { Screws and suture } \\
\text { anchors }\end{array}$ & 2019 & 13 & \\
\hline Roy Sh.., et al. & $\begin{array}{l}\text { Right side II } \\
\text { Left side III }\end{array}$ & Yes & Screw fixation & 2013 & 14 & \\
\hline
\end{tabular}

Table 1: The reported in the literature cases of Bilateral tubercle fractures.

The injury has been described as a result of a sudden eccentric contraction of the quadriceps with sudden knee flexion. Such fractures often occur during athletic activities, especially jumping $[18,30]$.

In regards to the demographics, there is a proclivity towards the male gender, due to greater involvement in vigorous athletic activities and a later age for the fusion of the upper tibial epiphysis. Type I and II fractures are frequent in adolescents from 12 to 14 years of age; thus type III fractures are most often are the most commonly observed in older adolescents from 15 to 17 years of age $[18,22]$.

The physeal closure of the proximal adolescent tibia follows a unique pattern; posteromedial to anterolateral in axial and the coronal planes and from proximal to distal in the sagittal plane, respectively $[19,20]$. This fact contributes significantly to the complexity and the 3-dimensional motif of this type of fractures.

There is a correlation between the Osgood-Schlatter's disease (OSD) and risk of tibial tubercle fracture. Many experts suggest restriction of jumping sports in adolescents $[3,12,18,30]$ with OSD until full consolidation in order to avoid possible fracture $[23,27,38]$.

Regarding the classification schemes, Watson originally [8] classified these fractures into three types:

- Type I: The tubercle is hinged upward without displacement from its proximal base;

- $\quad$ Type II: A smaller portion of the tubercle is avulsed without being completely fractured at its proximal base;
- Type III: The line of fracture extends into the knee joint with a displacement of the proximal base of the epiphysis).

Moreover, was modified by Ogden., et al. [10] who subdivided the three types into A and B (describing the comminution of the avulsed portion) and Ryu and Debenham [16,34-36] proposed the addition of type IV (propagation of the fracture line into the posterior tibial cortex)

The most common fracture pattern was type III [1-5].

The problem with the above classification scheme was that only a lateral plain x-ray is utilised. The concern is that injury is much more complex 3D injury pattern, articular and soft tissue involvement) [4]. Therefore, more advanced imaging modalities computer tomography (CT) [25] and magnetic resonance imaging (MRI) nowadays is used for preoperative planning and management.

Pandya., et al. [4] proposed a more comprehensive classification system, which addresses the complexity and can act as a guide for management and treatment.

\section{Type A}

Tubercle Youth: This pattern should be fixed with smooth Kwires as they frequently occur to skeletally immature cohorts (mean age, $12.7 \mathrm{y}$ ), avoiding insult of proximal tibial growth. It is important to note that the tip of the tubercle is the only partially ossified, and the remainder of the tubercle is cartilaginous in substance. Hence, it is not visible in the x-rays at this early stage of development but still can be injured. Articular involvement is rare, and advanced imaging is not necessary. 


\section{Type B}

Physeal: These injuries have a high risk of compartment syndrome and vascular injury [33]. Moreover, the clinician should be wary of this possibility. Because of the underestimation of injury severity and pattern by utilisation of plain lateral radiograph alone, and the proximity of these fracture types to the joint, further investigation with CT or with MRI $[25,26]$ scan warranted. This is crucial, as the vast majority of the patients with Ogden type II injuries (extra-articular/physeal) on plain film which underwent advanced imaging found to have intra-articular involvement (Ogden III) [1-5].

Fixation with smooth k-wires should be utilised to preserve the growth of the open proximal tibial physis.

\section{Type C}

Intra-articular: these injuries should undergo mandatory advanced imaging (as an intra-articular extension is notable in the plain film) to assess intraarticular fracture pattern and intraoperative arthrotomy or arthroscopy to assess soft tissue/chondral injury within the joint (and further assess articular congruity postreduction) [37-39]. As these patients have a higher degree of physeal closure, and the need to obtain an anatomic joint reduction is essential, more rigid, anatomic fixation with screws should be utilised, with CT scan or MRI determining screw placement $[25,26]$.

\section{Type D}

Tubercle Adolescent: these injuries rarely involve the joint, and tend to occur near the skeletal maturity (mean age, $15.5 \mathrm{y}$ ). Advanced imaging studies are not routinely recommended. Screw fixation in these adolescents is indicated as the physis has nearly closed.

Conservative treatment can be considered in these type of injuries. The displacement should be less than $2 \mathrm{~mm}$, without soft tissue interposition and intraarticular propagation. Immobilisation in extension with a cast or hinged knee brace for 4-6 weeks can be utilised $[1-3,6]$.

Intra-articular extension, leading to disruption of the articular surface, should be treated by open reduction combined with arthrotomy with the accurate anatomical restoration $[34,35]$.

The final choice of internal fixation devices should be made according to a well-stabilised fracture site to prevent displacement $[2,5,24]$. If growth potential in the proximal tibial remains, the position, type and the size of implants are crucial parameters [39].

Open anatomic reduction of the tibial articular surface and internal fixation is the treatment of choice for type III fractures despite their bilateral nature [5].

If growth potential in the proximal tibial remains, the implants should be inserted parallel to the joint plane, thereby avoiding insulting the growth plates [39].

The clinician should be vigilant for compartment syndrome development with vascular compromise (incidence approximately $4-20 \%)[1,4,11,33]$ because of the injury of the recurrent anterior tibial artery at the level of patellar tendon insertion. A prudent practise should involve a series of frequent examinations, and if the clinical suspicion is high, measurement of the compartments and fasciotomies are warranted.

One area of controversy is the practice of performing prophylactic fasciotomies at the time of the internal fixation; no clear consensus exists and relies on the surgeon's judgement [11,33].

In these types of fractures, the soft tissue injuries (meniscal, ligaments, periosteal stripping - especially with high-grade intraarticular injuries) are frequent [36-38]. Therefore, in the case of type III and IV fractures, advanced imaging studies (MRI) and arthrotomy or arthroscopy are required to address them adequately.

Growth related complications are relatively rare as the majority of the patients are near the skeletal maturity. Nevertheless, the genu recurvatum deformity is a well-documented complication $[1,2,4,6]$ due to physeal arrest of the anterior proximal tibial segment. Less commonly reported is a leg-length discrepancy as a result of vascular infiltration into the physis $[1,2,6]$.

Other complications include irritation and bursitis because of prominent hardware. The later is the most common complication following surgical treatment and may need another procedure for removal of the culprit $[12,13,17]$.

Failure to adequately reduce an intra-articular component of the fracture may lead to early post-traumatic arthritic changes [21,22].

Knee joint contracture and stiffness can follow both the operative and conservative treatment, especially after prolonged immobilisation $[1,2,4]$. 


\section{Conclusion}

In conclusion, the tibial tubercle fractures are infrequent but significant injuries. Early diagnosis and assessment is the key to the successful treatment. Surgical interventions around the tibial tubercle in skeletally immature individuals can lead to a wide range of complications such as angular deformity, in the coronal and in sagittal plane alike, a leg length discrepancy, angular deformity, premature physical closure and bursitis accompanied by stiffness. Non-operative treatment in selected cases combined with proper follow-up, can yield excellent results in terms of fracture healing and function.

\section{Informed Consent Statement}

Informed consent was obtained from all individual participants included in the study.

\section{Conflict of Interest}

The authors declare that they have no conflict of interest.

\section{Funding}

No funding to declare.

\section{Ethical Approval}

All procedures performed in studies involving human participants were in accordance with the ethical standards of the institutional and/or national research committee and with the 1964 Helsinki declaration and its later amendments or comparable ethical standards.

\section{Bibliography}

1. Pretell-Mazzini J., et al. "Outcomes and Complications of Tibial Tubercle Fractures in Pediatric Patients". Journal of Pediatric Orthopaedics 36.5 (2016): 440-446.

2. Riccio AI., et al. "Functional Outcomes Following Operative Treatment of Tibial Tubercle Fractures". Journal of Pediatric Orthopaedics 39.2 (2019): e108-e113.

3. Ergün M., et al. "Simultaneous bilateral tibial tubercle avulsion fracture in a basketball player". Knee Surgery, Sports Traumatology, Arthroscopy 11.3 (2003): 163-166.

4. Pandya NK., et al. "Tibial Tubercle Fractures". Journal of Pediatric Orthopaedics 32.8 (2012): 749-759.

5. Pace JL., et al. "Operatively Treated Type IV Tibial Tubercle Apophyseal Fractures". Journal of Pediatric Orthopaedics 33.8 (2013): 791-796.
6. Hamilton SW and Gibson PH. "Simultaneous bilateral avulsion fractures of the tibial tuberosity in adolescence: a case report and review of over 50 years of literature". The Knee 13.5 (2006): 404-407.

7. Mosier SM and Stanitski CL. "Acute Tibial Tubercle Avulsion Fractures". Journal of Pediatric Orthopaedics 24.2 (2004): 181184.

8. Watson-Jones R and Wilson JN. "Fractures and Joint Injuries". Edinburgh [U.A.] Churchill Livingstone (1976).

9. Alter AH. "Fracture of the tibial tubercle". Journal of Pediatric Surgery 12.4 (1977): 626.

10. Mubarak SJ., et al. "Classification of proximal tibial fractures in children". Journal of Children's Orthopaedics 3.3 (2009): 191197.

11. Pape JM., et al. "Compartment Syndrome Complicating Tibial Tubercle Avulsion". Clinical Orthopaedics and Related Research 295 (1993): 201-204.

12. Polakoff DR., et al. "Tension Band Wiring of Displaced Tibial Tuberosity Fractures in Adolescents". Clinical Orthopaedics and Related Research NA 209 (1986): 161-165.

13. Wiss DA., et al. "Type III Fractures of the Tibial Tubercle in Adolescents". Journal of Orthopaedic Trauma 5.4 (1991): 475479.

14. Christie MJ and Dvonch VM. "Tibial Tuberosity Avulsion Fracture in Adolescents". Journal of Pediatric Orthopaedics 1.4 (1981): 391-394.

15. Ogden JA., et al. "Fractures of the tibial tuberosity in adolescents". The Journal of Bone and Joint Surgery 62.2 (1980): 205215.

16. Ryu RKN and Debenham JO. "An unusual avulsion fracture of the proximal tibial epihysis.". Journal of Pediatric Orthopaedics 5.5 (1985): 630.

17. Frankl U., et al. "Avulsion fracture of the tibial tubercle with avulsion of the patellar ligament. Report of two cases". The Journal of Bone and Joint Surgery 72.9 (1990): 1411-1413.

18. Blanks RH., et al. "Flexion-Type Salter I1 Fracture of the Proximal Tibia Proposed Mechanism of Injury and Two Case Studies". Clinical Orthopaedics and Related Research 301 (1994): 256???259.

19. Shapiro F. "Pediatric Orthopedic Deformities: Basic Science, Diagnosis and Treatment". Apuk (2002). 
20. Dvonch VM and Bunch WH. "Pattern of Closure of the Proximal Femoral and Tibial Epiphyses in Man". Journal of Pediatric Orthopaedics 3.4 (1983): 498-501.

21. Todd TW. "The Anatomical Features of Epiphysial Union". Child Development 1.3 (1930): 186.

22. Wilson NHF and Gardner DL. "The microscopic structure of fibrous articular surfaces: A review". The Anatomical Record 209.2 (1984): 143-152.

23. Ogden JA and Southwick WO. "Osgood-Schlatter??s Disease and Tibial Tuberosity Development". Clinical Orthopaedics and Related Research NA 116 (1976): 180-189.

24. Ahn JH., et al. "Clinical Experience of the Tibial Plateau Fracture". Journal of the Korean Orthopaedic Association 25.3 (1990): 684.

25. Chan PSH., et al. "Impact of CT Scan on Treatment Plan and Fracture Classification of Tibial Plateau Fractures". Journal of Orthopaedic Trauma 11.7 (1997): 484-489.

26. Yacoubian SV., et al. "Impact of MRI on Treatment Plan and Fracture Classification of Tibial Plateau Fractures". Journal of Orthopaedic Trauma 16.9 (2002): 632-637.

27. Falciglia F., et al. "Osgood Schlatter Lesion: Histologic Features of Slipped Anterior Tibial Tubercle". International Journal of Immunopathology and Pharmacology 24 (2011): 25-28.

28. Gurbuz K. "Avulsion Fracture of the Tibial Tubercle Associated with Patellar Ligament Avulsion in a Sporting Adolescent: A Rare Case". Journal of Clinical and Analytical Medicine 7.4 (2014).

29. Kramer DE., et al. "Tibial Tubercle Fragmentation: A Clue to Simultaneous Patellar Ligament Avulsion in Pediatric Tibial Tubercle Fractures". Orthopedics 31.5 (2008): 1-4.

30. Franz P., et al. "Tibial tubercle avulsion fractures in children". Current Opinion in Pediatrics 32.1 (2020): 86-92.

31. Shin Y-W., et al. "Tibial tubercle avulsion fracture according to different mechanisms of injury in adolescents". Medicine 98.32 (2019): e16700.

32. Subbu R., et al. "Lessons learnt from managing an avulsion fracture of the tibial tubercle extending into the tibial physis". Case Reports 2013 (2013): bcr2013200551-bcr2013200551.

33. Alter AH. "Compartment syndrome as a complication of the hauser procedure". Journal of Pediatric Surgery 14.6 (1979): 866.
34. Curtis JF. "Type IV Tibial Tubercle Fracture Revisited”. Clinical Orthopaedics and Related Research 389 (2001): 191-195.

35. von Laer L. "Classification, diagnosis, and treatment of transitional fractures of the distal part of the tibia". The Journal of Bone and Joint Surgery 67.5 (1985): 687-698.

36. Choi N-H and Kim N-M. "Case Report Tibial Tuberosity Avulsion Fracture Combined With Meniscal Tear". Arthroscopy: The Journal of Arthroscopic and Related Surgery 15.7 (1999): 766769.

37. Falster $\mathrm{O}$ and Hasselbalch $\mathrm{H}$. "Avulsion fracture of the tibial tuberosity with combined ligament and meniscal tear". The American Journal of Sports Medicine 20.1 (1992): 82-83.

38. Lipscomb AB., et al. "Fracture of the tibial tuberosity with associated ligamentous and meniscal tears. A case report". The Journal of Bone and Joint Surgery 66.5 (1984): 790-792.

39. Hresko MT and Kasser JR. "Physeal arrest about the knee associated with non-physeal fractures in the lower extremity". The Journal of Bone and Joint Surgery 71.5 (1989): 698-703.

\section{Assets from publication with us}

- Prompt Acknowledgement after receiving the article

- Thorough Double blinded peer review

- Rapid Publication

- Issue of Publication Certificate

- High visibility of your Published work

Website: https://www.actascientific.com/

Submit Article: https://www.actascientific.com/submission.php Email us: editor@actascientific.com

Contact us: +919182824667 